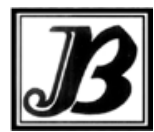

J. Bio-Sci. 27: 101-108, 2019

ISSN 1023-8654 http://www.banglajol.info/index.php/JBS/index DOI: https://doi.org/10.3329/jbs.v27i0.44675

\title{
THE GROWTH INFLUENCE OF ESCHERICHIA COLI CO-CULTURED WITH OTHER SELECTED GRAM NEGATIVE BACTERIA
}

\author{
OA Oyewole*, A Hamidu, IO Egbewole, R Adewole and OE Oladoja \\ Department of Microbiology Federal University of Technology Minna, Nigeria
}

\begin{abstract}
This study examined the influence of Escherichia coli on the growth of other selected Gram negative bacteria (Klebsiella pneumoniae, Shigella dysenteriae, Salmonella typhi, Pseudomonas aeruginosa and Proteus vulgaris). Cultures of each bacterium at 0,24, 48 and 72 hours of incubation were plated on MacConkey agar. Colonies that developed were counted while the optical densities were determined at $0,24,48$ and 72 hours using spectrophotometry. Each bacterium was co-cultured with $E$. coli and their growth was determined using culturing method and spectrophotometry. The result showed an increase in growth in the cultures of each isolate co-cultured with $E$. coli when compared with single bacterium culture with the exception of $P$. aeruginosa. The result of this study revealed a positive growth influence between $E$. coli and $K$. pneumoniae, S. dysenteriae, S. typhi, and $P$. vulgaris, except for $P$. aeruginosa that showed a decrease in growth.
\end{abstract}

Key words: Culturing, Escherichia coli, Gram negative bacteria, Interaction, Spectrophotometry

\section{Introduction}

The interactions amongst microorganisms and with their host are key strategies in their establishment and colonization in a wide variety of environments. These interactions include: metabolite exchange, chemotaxis, signalling, physiochemical changes, genetic exchange and metabolite conversion. Microbial interactions are important in the maintenance and establishment of a microbial population (Raíssa et al. 2016). Cooperation and conflict amongst microorganisms have been recognized as a factor that is important in the organization and function of microbial communities (Karoline and Jeroen 2012).

Bacteria rarely occur as a single entity, they often exist as biofilm, thereby resulting into a large variety of types of microbial interactions (Raíssa et al. 2016). Each bacterium secretes chemical signal molecules known as autoinducers that allows cells to interact and responds to their environment in a coordinated way (Phelan et al. 2012, Oyewole et al. 2017). A cell-cell signalling process is described among bacteria which accounts for their many cooperative behaviours (Kyle and Martins 2017). A regulatory phenomenon whereby cells excrete or secrete a chemical signal into the surrounding environment is known as Quorum sensing. At sufficient concentration the signal alters the expression of specific genes. Many Gram negative and Gram positive bacteria use quorum sensing signal circuits to coordinate various array of physiological behaviours, including conjugation, symbiosis, virulence, antibiotic production, competence, motility and biofilm development. A lot of Gram negative bacteria uses LuxR/LuxL type of quorum sensing, which is based on synthesis of diffusible signal molecules that is identified as $\mathrm{N}$-acyl-homoserine lactone (AHLs), to synchronize physiological behaviours (Fiorela et al. 2016).

\footnotetext{
*Author for correspondence: oa.oyewole@futminna.edu.ng
} 
Many years of coevolution that occurs among different species of microorganisms has led to cohabitation such as mutualistic and endosymbiotic relationships, antagonistic, pathogenic and parasitic relationship (Faust and Raes 2012, Nicole and Michiko 2016). Secondary metabolites have been reported to be greatly involved in microbial interactions as these compounds usually are bioactive and can perform important functions in ecological interactions. Antimicrobial host defenses and environmental factors also plays an important role by the communication of microorganisms, which enables the population to collectively regulate the gene expression in response to host and environmental signals that is produced by the same or different species. This results in a coordinate response in the microbial population by achieving successful pathogenic outcomes that would not be accomplished individually by their cells (Peters et al. 2012).

It has been reported that co-cultivation with other microorganisms from the same ecosystem can induce the activation of silent biosynthetic pathways leading to the production and identification of new natural products (Netzker et al. 2015). A lot of bacteria produce numerous public goods that are released into the extracellular environment of which this diffusion allows them to be used by the neighbouring organisms despite being produced for the individual, a good example of this are siderophores. Siderophores are related to competitive and cooperative microbial interactions and can play other roles such as signalling and antibiotic activity (Neilands 1995, Kannati and Senbagam 2014, Johnstone and Nolan 2015). Hopanoids, which is a secondary metabolite plays an important role also in bacterial interaction, confer tolerance and improves the adaptation of bacteria in different environments (Schmerk et al. 2015).

The interactions between Gram negative and other groups of bacteria could either be positive, negative or neutral. Many of Quorum sensing -regulated phenotypes exhibits a good sign of cooperation that results in the secretion of products that are produced by individuals with benefits that are available to all cells in a population. Examples are exoenzymes for the degradation of biopolymers, exopolysaccharide (EPS) for the formation of biofilms and antibiotics for microbial warfare (Kyle and Martin 2017). In an environment with individual microbes, mutualism is most often performed in order to increase individual fitness benefits while in a community; microorganisms interact on a large scale to allow for the persistence of the population, which will thereby increase their own fitness (Guimarães et al. 2016).

As bacteria are mostly found in colonies, neighbouring bacteria are likely to express genetic commonality thereby, increasing the chances for a nearby bacterium to grow and divide. In the case of siderophores production, positive correlation exists among bacterial lineages and siderophore production (Miethke and Marachiel 2007). Group selection is an important organizing principle of cooperation (James and Jeff 2012). In a microbial community composed of species that compete using different strategies, each of the individual cells possess a fitness that depends on the strategy of the individuals with whom it interacts. Individuals that use more successful strategies have higher chances to propagate and their frequency in the community will increase. Enzymes produced by bacteria that are responsible for the digestion of macromolecules such as extracellular lipases and proteases are good examples of public goods and their production in a complex microbial community is influenced by the interactions between its members (Matteo et al. 2017).

The interaction between one bacteria and other can lead to the depletion of the other bacteria population (Micheal et al. 2010). During the cooperative process, certain bacteria can switch to selfish behaviour in which they do not contribute to the production of public goods but benefits from the ones produced by others. If the ratio of the cheaters increases to a critical level, this may lead to the collapse of the community (Bige et 
al. 2016). Examples of antagonistic behaviour displayed by Gram negative bacteria include the secretion of toxins such as colicins or antibiotics that inhibit the growth of other bacteria (Glen et al. 2018). Cooperating bacterial populations are more likely to survive in changing habitats. Bacteria neutral interactions in its environment have impact on how best to cultivate bacteria strains and how to treat bacterial infections (Mauro and Erwin 2017). In nature, microorganisms interact with other microorganisms in the environment and the products from the microorganisms (Wikieł et al. 2014). Knowing how microorganisms interact would help in enhancing their products for biotechnological use and disease prevention. Therefore, the aim of this study was to assess the interaction between $E$. coli and other selected Gram negative bacteria.

\section{Materials and Methods}

\section{Microbial isolates}

The test organisms used for the study were Escherichia coli, Klebsiella pneumoniae, Salmonella typhi, Shigella dysenteriae, Pseudomonas aeruginosa, and Proteus vulgaris. The organisms were collected from culture collection centre of the Centre for Genetic Engineering Federal University of Technology, Minna, Nigeria. The organisms were stored in slant bottles in the refrigerator at temperature of $4^{\circ} \mathrm{C}$.

\section{Confirmatory tests on the organisms}

The organisms were confirmed using cultural and biochemical characterization. The media used for this work were nutrient broth and MacConkey agar. The tests carried out were Gram staining, indole test, citrate utilization test, oxidase test using test tube method, catalase test, urease test, methyl red test, Voges Proskaeur test and sugar fermentation test (Cheesbrough 2006).

\section{Assessment of the interaction between $E$. coli and other selected Gram negative bacteria}

The $9 \mathrm{ml}$ of nutrient broth was dispensed into 6 test tubes and sterilized at $121^{\circ} \mathrm{C}$ for 15 minutes. The $0.5 \mathrm{ml}$ pure culture of each test organism was inoculated into each of the test tube and incubated for 24 hours at $37^{\circ} \mathrm{C}$. The $0.1 \mathrm{ml}$ culture was plated on MacConkey agar to confirm the purity of the culture. The $9 \mathrm{ml}$ of nutrient broth was also dispensed into 12 test tubes and $0.5 \mathrm{ml}$ overnight culture of each test organism was inoculated into each of the test tubes and incubated for 24 hours at $37^{\circ} \mathrm{C}$. For cultures co-cultured with $E$. coli, $0.5 \mathrm{ml}$ of both organisms was inoculated into the test tube. Serial dilution was carried out on each culture (singly and combined) at 0, 24, 48 and 72 hours of incubation and fifth diluent was plated using 0.1 $\mathrm{ml}$ of the organism on MacConkey media plate using pour plate method. Colonies were counted while the optical densities were also determined using UV-VIS spectrophotometry (model 752, China).

\section{Results}

\section{Optical densities of $E$. coli and other selected Gram negative bacteria}

Each growth of the test organism in the medium appears turbid and the growth was determined using spectrophotometry. The result is indicated in Fig. 1. There was generally an increase in the optical densities as the incubation period increases from 0 to 72 hours. Thus, highest optical densities (turbidity) were observed on the last day of incubation (72 hours). There was an increase in the optical densities of $S$. dysenteriae, S. typhi, K. pneumonia and Proteus vulgaris co-cultured with E. coli compared to the single cultures. However, there was a decrease in the optical density of $P$. aeruginosa co-cultured with $E$. coli compared with single cultures of $P$. aeruginosa. 


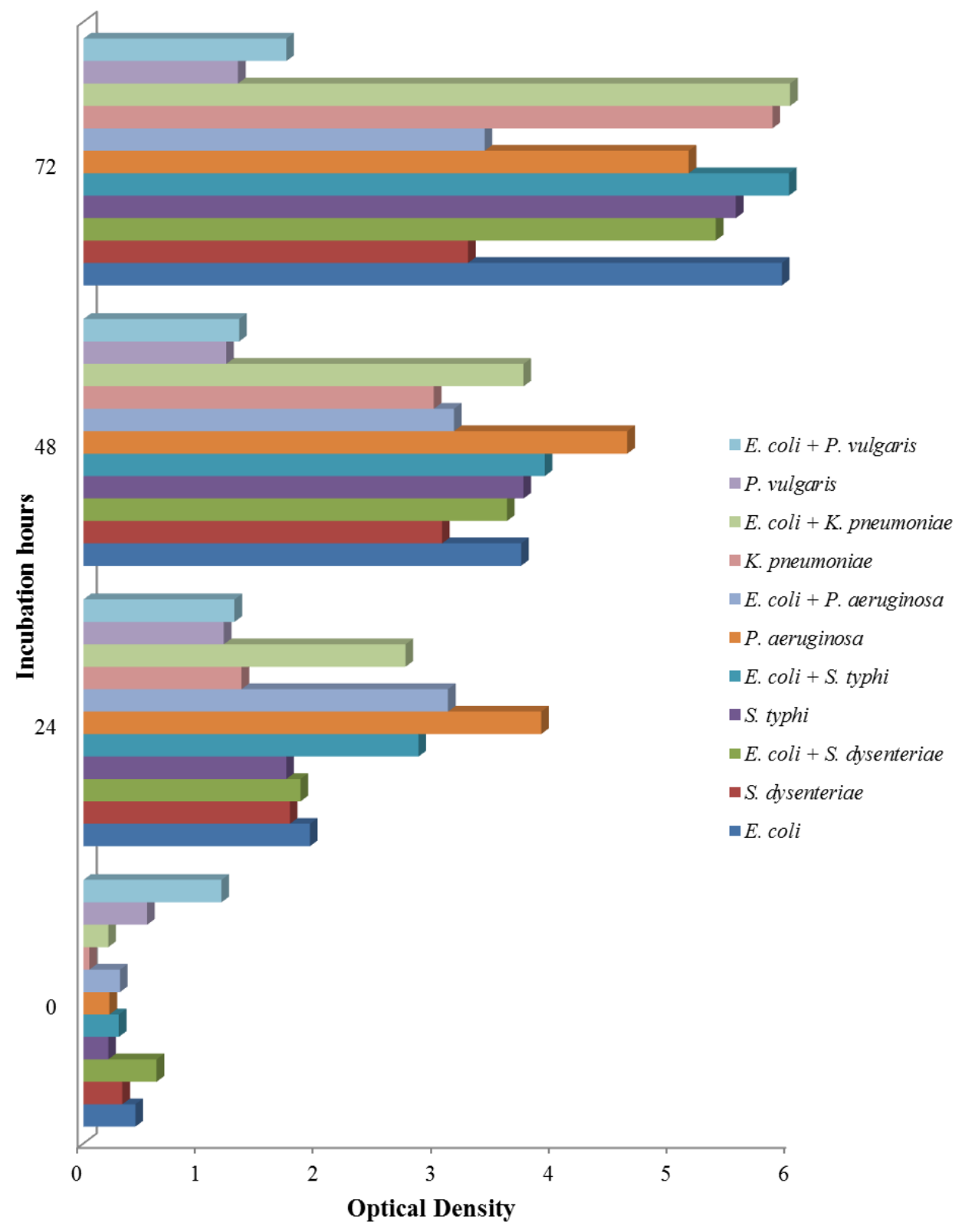

Fig. 1. Optical densities of $E$. coli and other selected Gram negative bacteria.

The interaction between each organism and $E$. coli was positive and the growth of colony increases with increase in incubation period as shown in Fig. 2, still with the exception of $P$. aeruginosa. 


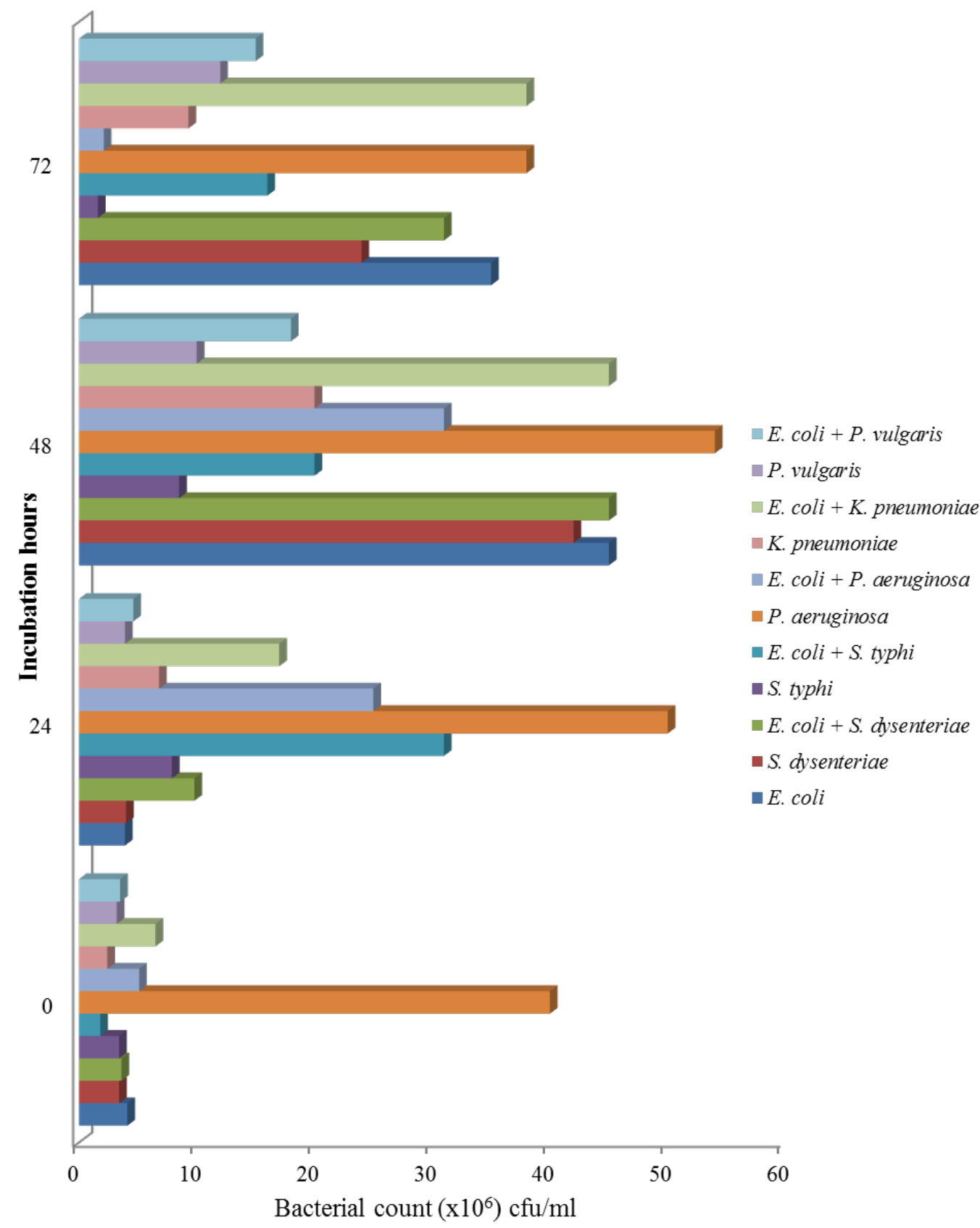

Fig. 2. Colony count of $E$. coli and other selected Gram negative bacteria. 


\section{Discussion}

The influence of $E$. coli on the growth of $P$. aeruginosa, S. typhi, S. dysenteriae, K. pneumoniae and $P$. vulgaris was carried out in this study. The growth that exists between $E$. coli and the other four Gram negative bacteria was determined by optical densities using spectrophotometry (Fig. 1) and by colonial count (Fig. 2). The increased optical densities and bacterial counts observed in $E$. coli in test tubes co-cultured with other bacteria compared to single colonies may be due to the secretion of products through cell-to-cell signal systems (Høiby et al. 2010) or exhibition of quorum sensing-regulated phenotypes by $E$. coli that has benefits to the growth of the other Gram negative bacteria in the medium. Kyle and Martin, (2017) argued that $E$ coli produces a lot of public goods that are used by other Gram negative bacteria such as extracellular lipases and proteases, siderophores, exoenzymes use for the degradation of biopolymers, exopolysaccharide (EPS) for the formation of biofilms and antibiotics for microbial warfare. In quorum sensing, each bacterium secretes chemical signal molecules known as auto-inducers (Al). As bacterial density increases, the level of the auto-inducers in the immediate environment also increases and this increases their interaction with cell signal receptors on surrounding bacteria (Fuqua and Greenberg 1998).

The optical densities of E. coli, P. aeruginosa, S. typhi, S. dysenteriae, K. pneumoniae increase with increase in hours of incubation which implies multiplication of cells in the medium. This implies that the interaction between $E$. coli and the other Gram negative is favourable to them and it is not detrimental to $E$. coli itself. It has been established that bacteria interact with other organisms in vitro and in vivo. Neilands (1995) which explains that, a lot of bacteria produce numerous public goods that are released into the extracellular environment of which this diffusion allows them to be used by the neighbouring organisms despite being produced for the individual. This is as a result of $E$. coli expressing genetic commonality thereby, increasing the chances for the nearby bacterium to grow and also $E$. coli produces siderophore that enhances the growth of the other Gram negative bacteria in agreement to Miethke and Marachiel (2007) which explains that bacteria are mostly found in colonies, neighbouring bacteria are likely to express genetic commonality, thereby increases the chances for a nearby bacterium to grow and divide.

The interaction between $E$. coli and $K$. pneumoniae in humans is an example. This interaction leads to respiratory disease in mule foals (Carneiro et al. 2017). E. coli and K. pneumoniae interaction leads to the resistant of carbapenem-resistance of which the carbapenemase are OXA-48 and NDM producers (Hosam et al. 2014). Similarly, Salmonella evolved to aid $E$. coli by excreting amino acids. In lactose media, Salmonella consumes metabolic waste from $E$. coli creating a mechanism of reciprocation for cooperation (Harcombe 2010). The interactions between E. coli and S. typhi may lead to infections, which may also lead to transfer of resistance to antimicrobial drugs (Moini et al. 2015). The opportunistic pathogens use hierarchical quorum-sensing network to regulate virulence factor production that cooperatively benefit the population at a cost to the individual (Ron et al. 2018). During the interaction between these two organisms, Freya et al. (2006) asserts that $P$. aeruginosa produces siderophores that results in more rapid host death thereby, causing mixed infections.

Mohandass (2004) also reported that siderophores are mostly novel compounds and contain many modified amino acids that are naturally not found elsewhere. Also, Martinez et al. (2003), Ali and Vidhale (2013) and Ahmed and Holmström (2014) added that siderophores have several biotechnological, agricultural, environmental and medicinal applications. According to Martinez et al. (2003), most bacteria synthesize one or more types of siderophores, which are often secreted into the growth medium.

There was an increased growth of all the other Gram negative bacteria co-cultured with $E$. coli with the exception of $P$. aeruginosa. This may be because $P$. aeruginosa does not utilize the metabolic products produced by $E$. coli for its growth instead makes use of the nutrient in the medium. It may also be as a result 
of secretion of toxins by $E$. coli that is harmful to $P$. aeruginosa in the medium. Zuo (2007) reported the production of compounds by Paenibacillus polymyxa and Bacillus licheniformis that inhibit the growth of sulphate reducing bacteria. The result of this study revealed a positive effect of $E$. coli on the growth of all other selected Gram negative bacteria with the exception of $P$. aeruginosa that showed a decrease in growth when co-cultured with $E$. coli. Further studies need to be carried out on the identity of substances that are secreted by $E$. coli that confer growth induction or growth inhibition to these bacteria.

\section{References}

Ahmed E and Holmström SJM (2014). Siderophores in environmental research: roles and applications. Microbial Biotechnology, 7: 196-208.

Ali SS and Vidhale NN (2013). Bacterial siderophore and their Application. A Review. International Journal of Current Microbiology and Applied Sciences, 2(12): 303-312.

Moini AS, Soltani B, Ardakani AT, Moravveji A, Erami M, Rezaei MH and Namazi M (2015). Multidrug-resistant E. coli and Klebsiella pneumoniae isolated From Patients in Kashan, Iran. Jundishapur J Microbiol, 8(10): 1-8.

Bige DU, Sasitharan B and lan FA (2016). The impact of social behaviour on the attenuation and dekay of bacterial nanonetworks. IEEE Transactions on Nanobioscience, 15(8): 960-968.

Carneiro VC, Lessa DA, Guttman, PM, Magnelhae, H, Aquino MH, Cunha LE, Arais LR and Cerqueira AM (2017). Virulence, resistance and genetic relatedness of Escherichia coli and Klebsiella sp. isolated from mule foals. Verterinariae Zootecnia, 69(5): 1678-4162.

Cheesebrough M (2006). District laboratory practice in tropical countries. Part 2. Low price Edition, Cambridge University Press London, pp. 26.

Faust K and Raes J (2012). Microbial interactions from networks to models. National Review Microbiology, 10: 538-550.

Fiorela LN, Pablo CB and Walter G (2016). Programmed Lab Experiment for Biochemical investigation of Quorumsensing signal molecules in Rhizospheric soil Bacteria. Biochemistry and Mol. Biology Education, 44(3): 256-262.

Fuqua C and Greenberg EP (1998). Self-perception in bacteria: quorum sensing with acylatedhomoserine lactones. Journal of Current Opinion in Microbiology, 1: 183-189.

Glen DS, Shraddha S, Daniel P, Ghada Y, Silivio W and Christian K (2018). Ecology and evolution of metabolic crossfeeding interactions in bacteria. Royal Society of Chemistry, 35: 455-488.

Guimarães PR, Pires MM, Marquitti FM and Raimundo RL (2016). Ecology of Mutualism. Wiley, Hoboken, NJ, pp. 1-9.

Høiby N, Bjarnsholt T, Givskov M, Molin S and Ciofu O (2010). Antibiotic resistance of bacterial biofilms. International Journal of Antimicrobial Agents, 35: 322-332.

Harcombe W (2010). Novel cooperation experimentally evolved between species. PubMed Mobile, 64(7): 2166-2172.

Hosam MZ, Anna LS, Hanan HB, Reem YA, Mubarak A, Emad I, Amina AJ, Seif AB, Jameela AS, Ali AD, Abdullah HK, Sanmarie S, Hanna ES and David LP (2014). Molecular characterization of carbapenemase-producing Escherichia coli and Klebsiella pneumoniae in the countries of the Gulf Cooperation Council: Dominance of OXA-48 and NDM producers. Antimicrobial Agents and Chemotherapy, 58(6): 3085-3090.

James AD and Jeff G (2012). Understanding microbial cooperation. US National Library of Medicine National Institutes of Health, 299: 31-41.

Johnstone TC and Nolan EM (2015). Beyond iron: non-classical biological functions of bacterial siderophores. Dalton Translation, 44: 6320-6339.

Kannati M and Senbagam N (2014). Studies on siderophore production by microbial isolates obtained from rhizosphere soil and its antibacterial activity. Journal of Chemical and Pharmaceutical Research, 6(4): 1142-1145. 
Karoline F and Jeroen R (2012). Microbial interactions: from networks to model. Nature Reviews, 10: 538-550.

Kyle LA and Martin S (2017). Social interactions in bacterial cell-cell signalling. FEMS Microbiology, 41(1): 92-107.

Martinez JS, Carter-Franklin JN, Mann EL, Martin JD, Haygood MG and Butler A (2003). Structure and membrane affinity of a suite of amphiphilic siderophores produced by a marine bacterium. Proceedings of the National Academy of Sciences, 100(7): 3754-3759

Matteo C, Song F, Orkun SS and Jose IJ (2017). Cooperation in microbial communities and their biotechnological applications. Environmental Microbiology, 19(8): 2949-2963.

Mauro M, Erwin F and Karl W (2017). Fluctuating environments can help cooperating bacteria. Science Daily. https://www.sciencedaily.com/.

Mohandass C (2004). Bacterial siderophores and their biotechnological applications, In: N Ramaia (Ed.), Marine Microbiology: Facets and Opportunities India: National Institute of Oceanography, pp. 169-174.

Michael EH, Clay F, Matthew RP and Brook SP (2010). Bacteria Competition Surviving and thriving in the microbial jungle. National Review Microbiology, 8(1): 15-25.

Miethke M and Marahiel MA (2007). Siderophore-based iron Acquisition and pathogen control. Microbiology Molecular Biology Review, 71: 413-451.

Neilands JB (1995). Structure and function of microbial iron transport compounds. J. Biology Chemical, 270(45): 26723.

Netzker T, Fischer J and Weber J (2015). Microbial communication leading to the activation of silent fungal secondary metabolite gene clusters. Front Microbiology, 6: 299.

Nicole AA and Michiko ET (2016). Decoding molecular interactions in microbial communities. FEMS Microbiology Review, 40(5): 648-663.

Oyewole OA, Adelere TA, Shaba AM, Ojah S, Ayisa TT and Egbewole IO (2017). Cell-to-cell signal system in Escherichia coli drug resistance (A review). International Research Journal of Environmental Sciences, 6(8): 51-59.

Peters BM, Jabra-Rizk MA, O'May GA, Costerton JW and Shurtliff ME (2012). Polymicrobial interactions: impact on pathogenesis and human disease. Clinical Microbiology Review, 25: 193-213.

Phelan VV, Liu WT, Pogliano K and Dorrestein PC (2012). Microbial metabolic exchange the chemotype-to-phenotype link. National Chemical Biology, 8: 26-35.

Raíssa MB, Manuella ND and Welington LA (2016). Microbial interactions: ecology in a molecular perspective. Brazilian Journal of Microbiology, 47(1): 86-98.

Ron DO, Keren SZ and Avigdor E (2018). Selection for increased Quorum-sensing cooperation in Pseudomonas aeruginosa through the slut down of a drug resistance pump. The ISME Journal, 12: 2458-2469.

Schmerk CL, Welander PV and Hamac MA (2015). Elucidation of the Burkholderia cenocepacia hopanoid biosynthesis pathway uncovers functions for conserved proteins in hopanoid-producing bacteria. Env. Microbiology, 17: 735-750.

Wikieł AJ, Datsenko I, Vera M and Sand W (2014). Impact of Desulfovibrio alaskensis biofilms on corrosion behaviour of carbon steel in marine environment. Bioelectrochemistry, 97: 52-60.

Zuo R (2007). Biofilms: strategies for metal corrosion inhibition employing microorganisms. Applied Microbiology and Biotechnology, 76(6): 1245-1253.

(Manuscript received on July 23, 2018 and revised on December 29, 2018) 